\title{
Implementation of Models for reheating processes in industrial furnaces
}

\author{
Daniel Rene Kreuzer Andreas Werner \\ Vienna Universtiy of Technology, Institute of Energy systems and Thermodynamics \\ Getreidemarkt 9/302, 1060 Wien
}

\begin{abstract}
Components were developed for the modeling of industrial furnaces in the iron and steel industry like pusher-type and walking beam furnaces. A cell model on the basis of the dynamic pipe model of the Modelica Fluid Library was designed. The cell model computes the heat transfer between furnace walls, flue gas and the processed steel goods. The radiative heat transfer is modeled by a 1-dimensional method based on Hottel's net radiation method. Furthermore, models for furnace walls, slabs, hearth and the transport of the slabs were designed. The models are suitable for analyzing operation modes and designing control concepts
\end{abstract}

Keywords: reheating; furnace; simulation; radiation

\section{Introduction}

Currently the manufacturing industry has focused on increasing energy efficiency of their production processes. The effective and sustainable use of energy is becoming more important, due to the issues of climate change and therefore the demand of reducing $\mathrm{CO}_{2}$ emissions. The iron and steel industry in particular incorporates a multiplicity of reheating processes in the production chain of their commodities. For instance the reheating of slabs in pusher type or walking beam furnaces to set up the right temperature interval before hot rolling as well as annealing of steel coils in continuous or batch furnaces to trigger the micro structure and therefore the properties of the steel products. The furnaces mentioned are commonly operated by using natural gas and off gas from blast furnace, coke oven and basic oxygen furnace. While in the past the development of reheating processes was concentrated on increasing the production output, recently the decrease in energy consumption became more and more important. Raising energy efficiency requires the optimization or redesign of the reheating process steps,

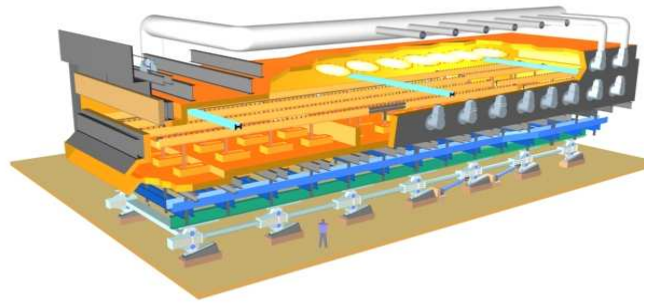

Figure 1: Walking beam furnace

e.g. by implementing advanced control concepts or by analyzing and assessing different operation modes. These engineering tasks indicate the need for accurate dynamic furnace models. There exists a variety of furnace models as e.g. described in [5],[8], [4], [2]. Several models which are used by the industry are based on experimental modeling (system identification) or so called black box modeling. The disadvantage of such models is the restricted validity to the considered systems. The main intention of the presented work is the design of highly reusable models contained within a library which are able to simulate the unsteady heat transfer phenomena of reheating steel goods in industrial furnaces. Due to the focus on modeling the physical phenomena and the reuse ability of the models the Modelica language standard and the simulation environment Dymola were chosen for the modeling task.

\section{Basic considerations}

Figure 1 shows the layout of a typical reheating furnace which can be used for heating semi-finished steel products before hot rolling. Basically they work as counter current heat exchangers, therefore the transport direction of the processed goods is di- 


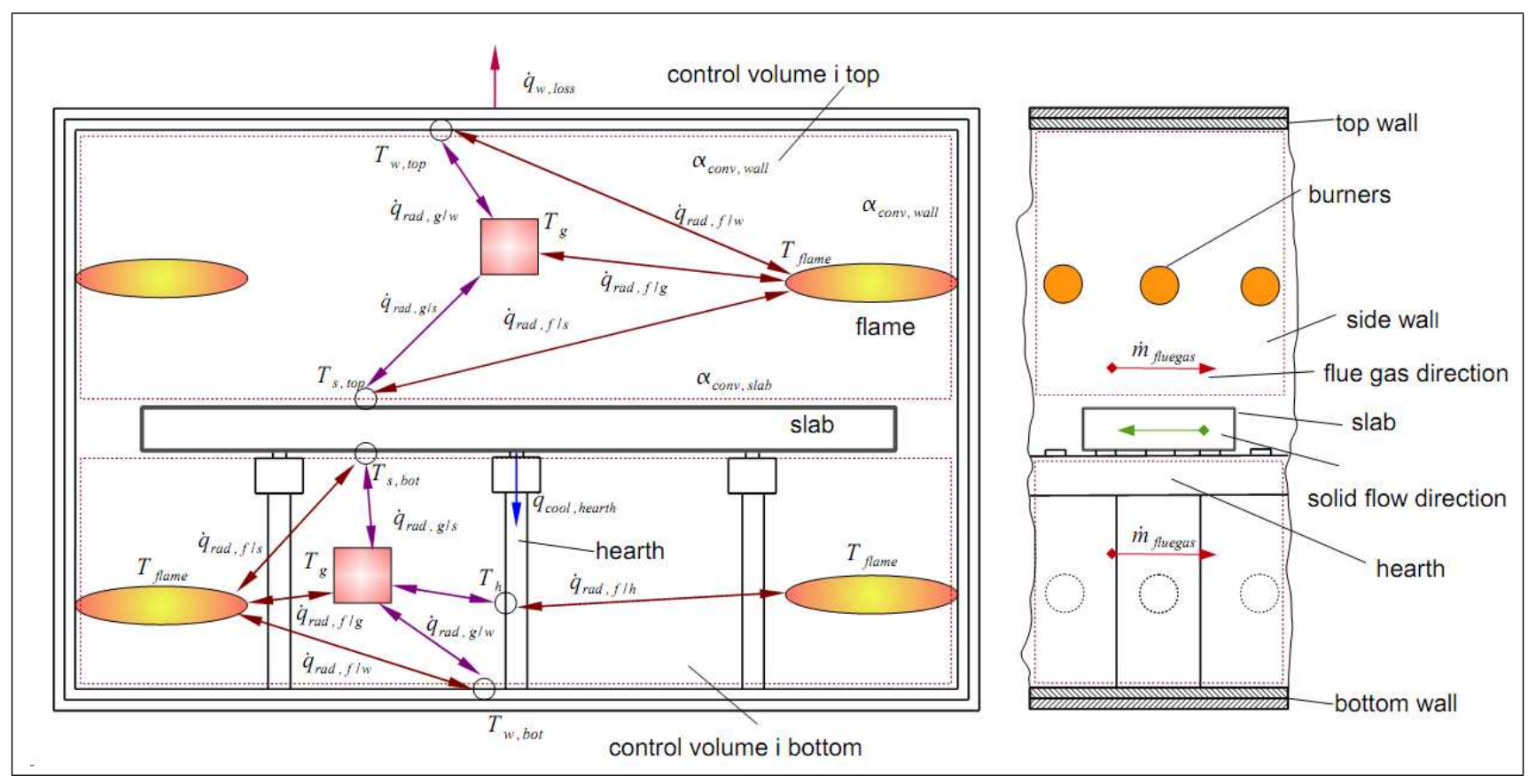

Figure 2: Heat transfer mechanisms of reheating process

rected against the main flow of the flue gas. Reheating furnaces usually consist of a convective, heating and soaking zone. The heating and soaking zone are commonly operated by gaseous fuel-type burners, and the main heat transfer phenomenon is radiation. Due to the high flue gas temperatures up to $1400{ }^{\circ} \mathrm{C}$, furnaces are lined with refractory. The walls have a typical multiple layer configuration of different materials. During processing, the steel goods are positioned on a hearth, which has to be cooled for e.g. by evaporative cooling. The basic phenomena of reheating processes which have to be modeled are

- Heat transfer due to radiation between walls, flue gas, flame and processed goods

- Heat transfer due to convection between flue gas and walls as well as flue gas and processed goods

- Heat conduction in furnace walls, processed goods and hearth

- Combustion of gases (burners)

- Transport of flue gas - Fluid Flow Models (FFM)

- Transport of processed goods - Solid Flow Models (SFM)

Figure 2 depicts the appearing heat flow rates of reheating slabs in a walking beam furnace. The further presented models consider primarily the reheating of slabs in walking beam or pusher-type furnaces. However the models for heat transfer phenomena are generally valid and may only need a minor adaptation for use at other reheating processes. The major diversities in modeling reheating processes are evident for the SFM and their impact on the heat transfer models.

\section{Fluid Flow}

The general concept of the reheating process models is based on a homogeneous cell model which incorporates fluid flow and heat transfer. The dynamic pipe flow model of the Modelica.Fluid.Library is used for modeling the 1-dimensional fluid flow of flue gases in the furnaces. A comprehensive description of solving the fluid transport equations with the Modelica.Fluid.Library is given in [3]. Properties of the fluids are determined by the Modelica.Media.Library, e.g. internal energy, specific enthalpy, density, thermal conductivity, dynamic viscosity. The heat transfer between the gases, the walls and the slabs is realized by designing a new heat transfer model which replaces the standard models. 

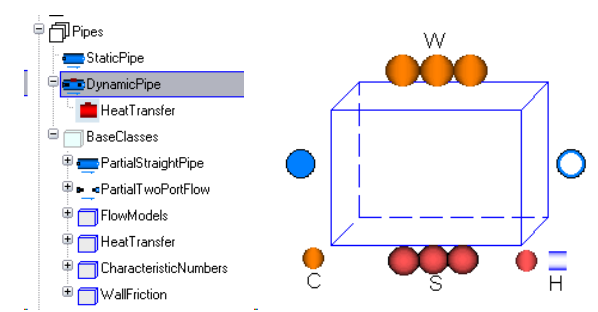

Figure 3: Cell model based on Modelica fluid library

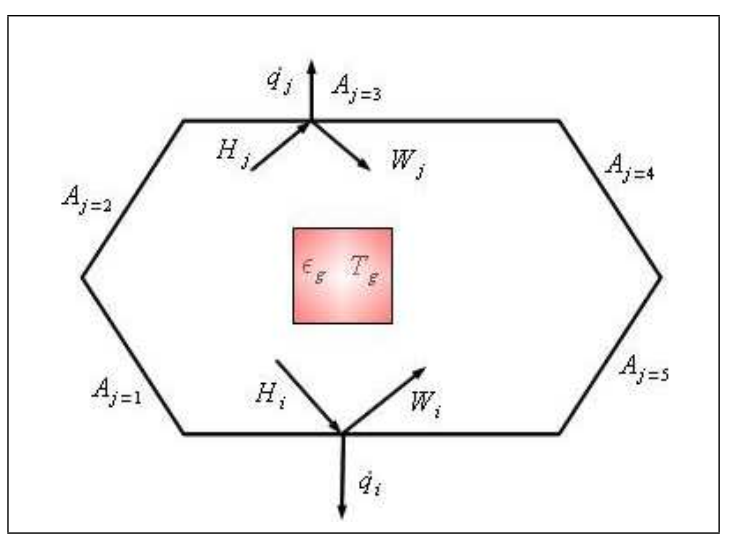

Figure 4: Net radiation heat flow of surface $i$ in a cell containing the emitting gas

\section{Heat Transfer}

\subsection{Radiative heat transfer}

The radiative heat transfer plays a key role in modeling high temperature industrial furnaces. The different mathematical radiation models can be classified by their dimensionality. in literature 0-dimensional, 1 dimensional and 3-dimensional models are discribed. 3D-models achieve the highest accuracy but require high efforts in modeling and computing time, those kind of models are usually implemented in commercial CFD-packages. 0D-models are based on the stirred-tank reactor and give only a rough estimation for the radiative heat transfer of the regarded systems. 1D-models are in between the two aforementioned types and seem to be a proper trade-off in accuracy and modeling effort. For modeling the radiative heat transfer a 1D-model derived by [6] was selected. It has been developed from the net radiation method of Hottel, which is described in [7], [1]. Scholand [6] depicts the equations needed for calculating radiative heat exchange between radiating surfaces in an enclosure comprising isothermal radiative gases.

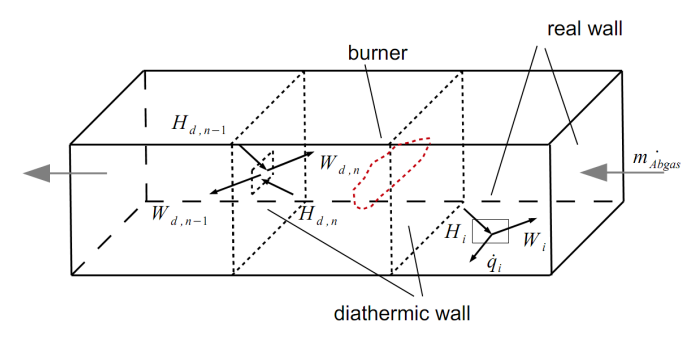

Figure 5: Discretization of a combustion chamber

\subsubsection{Governing Equations}

The following section states the equations according [6] used for the radiative heat transfer model. The grey and diffuse radiating surface $A_{i}$, shown in Figure 4 , receives the radiative heat flow $H_{i}$ composed of the heat flow emitted by the different grey surfaces and the gas. The grey surface $i$ again emits with its temperature $\varepsilon_{i} E_{b i}$ and reflects $H_{i} \rho_{i}$. The net-radiation heat flow of the surface $i$, which exchanges heat with $n$ different surfaces of the enclosure, yields

$$
\dot{q}_{i}=W_{i}-H_{i}
$$

at which the outgoing radiative heat flow is given by

$$
W_{i}=\varepsilon_{i} \cdot E_{b i}+\rho_{i} \cdot H_{i}
$$

$\varepsilon_{i}$ is the emissivity of the grey wall and $E_{b i}=\sigma \cdot T_{i}^{4}$ is the hemispherical total emissive power of a black body whereas $\sigma$ is the Stefan-Boltzmann constant and $T_{i}$ the surface temperature. The incoming radiative heat flow is given by

$$
H_{i}=\varepsilon_{g i} \cdot \sigma T_{g}^{4}+\frac{1}{A_{i}} \sum_{j=1}^{n} A_{j} W_{j} F_{j i} \tau_{j i}
$$

and equation 1 results in

$$
\dot{q}_{i}=\varepsilon_{i} \cdot E_{b i}-\varepsilon_{i} \cdot \varepsilon_{g i} \cdot \sigma T_{g}^{4}-\varepsilon_{i} \cdot \frac{1}{A_{i}} \sum_{j=1}^{n} A_{j} W_{j} F_{j i} \tau_{j i}
$$

$\varepsilon_{g i}$ is the emissivity of the gas and $T_{g}$ is the gas temperature. $W_{j}$ is the outgoing heat flow of the $\mathrm{j}^{\text {th }}$ surface element, $A_{i}$ and $A_{j}$ are the associated surface areas, $F_{j i}$ is the view configuration factor between surface $\mathrm{j}$ and surface $\mathrm{i}$ and $\tau_{j i}$ is the transmittance of the gas. The discretization of a furnace is done by connecting several of the above described cells. The heat transfer due to radiation between those cells is realized by a diathermic wall approach depicted in figure 5. The diathermic wall presents the interface between 
two cells, e.g. the relation between cell $n$ and the cell $n-1$ yields:

$$
\begin{aligned}
& H_{i, n}=W_{i, n-1} \\
& H_{i, n-1}=W_{i, n}
\end{aligned}
$$

The above stated equations presume a grey gas entirely surrounded by grey walls. For a grey gas the dependency of emissivity, absorptivity and transmittance is given by $\alpha_{g}+\tau_{g}=1, \alpha_{g}=\varepsilon_{g}$ and $\rho_{g}=0$, whereas for a grey body $\tau=0, \alpha+\rho=1$ and $\varepsilon=\alpha$. A real gas like flue gas from a combustion reaction is composed of several species which have different properties. Important radiative gases like $\mathrm{CO}_{2}$ and $\mathrm{H}_{2} \mathrm{O}$ are selective emitters which means their emissivity, absorptivity and transmittance strongly depend on the wave length interval. Due to this fact the assumption of a single grey gas surrounded by grey walls has to be abandoned whereas the assumption of grey body radiation of the walls remains valid. Therefore the equation 4 yields:

$$
\begin{gathered}
\dot{q}_{i}=\varepsilon_{i} \cdot E_{b i}-\varepsilon_{i} \cdot \int_{\lambda=0}^{\infty} \varepsilon_{\lambda g i} \cdot \sigma T_{g}^{4} d \lambda \\
-\varepsilon_{i} \cdot \frac{1}{A_{i}} \int_{\lambda=0}^{\infty} \sum_{j=1}^{n} A_{j} W_{j} F_{j i} \tau_{j i} d \lambda
\end{gathered}
$$

The clear-gray gas model approach according to [9] is used for the calculation of the emissivity, absorptivity and transmittance of the gas mixture. The emitting species are considered as grey gases and the other species are concentrated as non emitting clear gas. The emissivity of a gas mixture with $\mathrm{H}_{2} \mathrm{O}$ and $\mathrm{CO}_{2}$ as emitting gases is hence:

$$
\varepsilon_{G}=\sum_{i=1}^{3} a_{i}\left(1-e^{-k_{g i} \cdot p_{g} \cdot S_{G}}\right)
$$

where $k_{g i}$ is the absorption coefficient of the different constituents, $p_{g}$ equals the sum of the partial pressure of $p_{\mathrm{H}_{2} \mathrm{O}}$ and $p_{\mathrm{CO}_{2}}, S_{G}$ is the radiation beam length and $a_{i}$ are weighting factors which are given by a linear approach

$$
a_{i}=b_{0 i}+b_{1 i} \cdot T_{G}
$$

and the conditional equation

$$
\sum_{i=1}^{3} a_{i}=1
$$

The absorptivity is calculated with a similar approach to equation 9 and 10, only the weighting factors are determined with the wall temperatures instead of the gas temperature. For solving the equations of the radiative heat transfer the calculated radiative gas properties are applied to equation 4 .

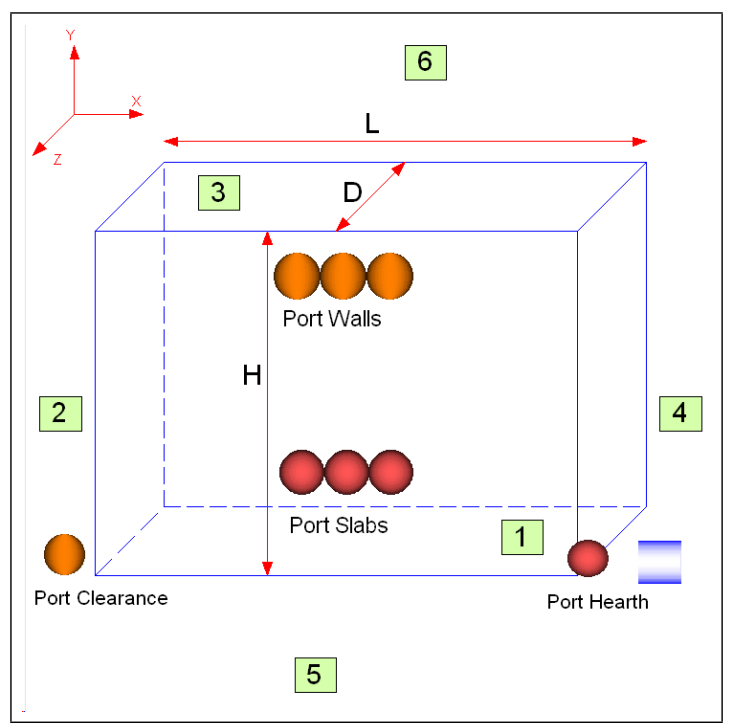

Figure 6: Cell model for heat transfer

\subsection{Convective heat transfer}

The convective heat transfer can simply be added to the net-radiation equation of the surface $\mathrm{i}$

$$
\begin{aligned}
& \dot{q}_{i}=W_{i}-H_{i}+\dot{q}_{c o n v} \\
& \dot{q}_{c o n v}=\alpha \cdot\left(T_{g}-T_{i}\right)
\end{aligned}
$$

The heat transfer coefficients for the single surfaces are determined with the relation of forced convection at a single plate according to [9]

\subsection{Thermal conduction}

The transient heat conduction problem in walls, slabs and hearth is modeled by Fourier's 1-dimensional partial differential equation

$$
\frac{\partial T}{\partial t}=a \cdot \frac{\partial^{2} T}{\partial x^{2}}+\frac{\dot{Q}_{e}}{\rho c_{p}}
$$

\subsection{Implementation of heat transfer models}

\subsubsection{Radiation and convection models}

The net-radiation method and the convective heat transfer equations presented in section 4.1 and 4.2 were integrated into a new designed model RadiationAndConvectionHeatTransfer . The model calculates all the data necessary for the heat transfer mechanisms, e.g. the view configuration factors of the involved bodies, the radiative properties of the gases, the Nußelt-Numbers, the convective heat transfer coefficients etc. Those data in conjunction with the temperatures lead finally to the net-radiation 


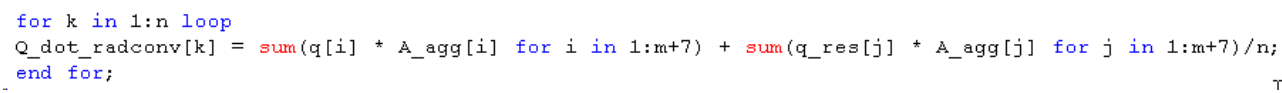

Figure 9: Code for computation of Qb_dot_radconv for a single cell

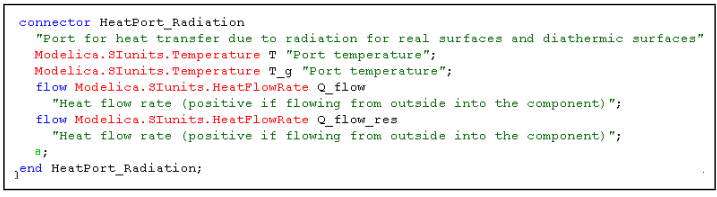

Figure 7: HeatPort_Radiation Connector

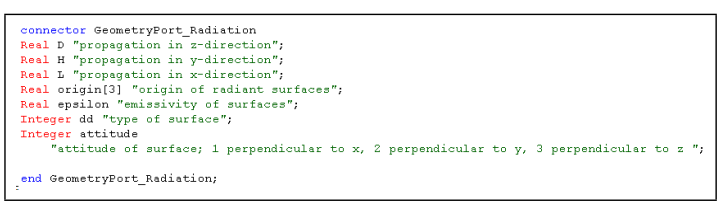

Figure 8: GeometryPort_Radiation Connector

and convective heat flows. A bottom-cell and a top-cell are developed for the discretization of the furnaces to take the different geometric configurations into account. For the energy exchange between fluid, walls, slabs, hearth and the neighbouring cells a new type of connectors HeatPort_Radiation was developed. It is not working like real physical connector due to the fact that it may be connected to diathermic walls. A diathermic wall usually represents the interface between two discretized cells. Unlike a real wall a diathermic wall has to enable a heat flow in both directions at the same time. Therefore another flow variable Q_flow_res and the corresponding potential variable $T_{-} g$ which is equal to the gas temperature of the cell were introduced. The radiative heat transfer depends on the temperature differences of the involved bodies and it depends on the position, attitude, propagation and emissivity of the emitting surfaces. That fact leads to a further none physical connector GeometryPort_Radiation which transmits the necessary data from the involved bodies to the heat transfer model and vice versa. The generated connectors are combined to composite connectors. Figure 6 shows the heat transfer model of a top-cell and the connections to walls, slabs and the hearth. Two further connectors are present one which sends a signal with needed data for heat conduction between slabs and hearth and the other one which realizes a heat flow due to radiation between a top and a bottom cell via a diathermic wall.

The connection between the heat transfer model and the fluid flow model is made via the energy balance

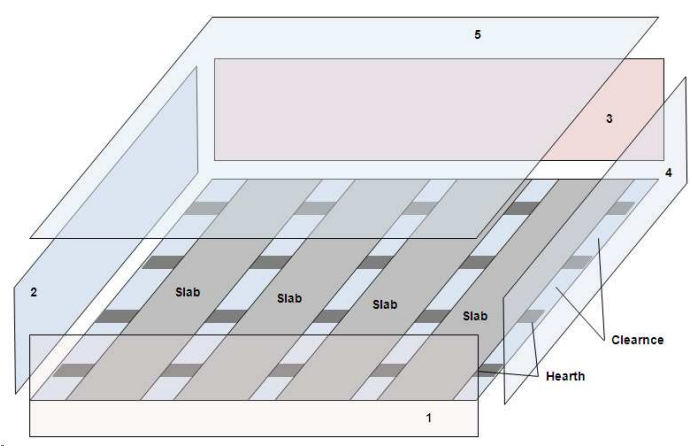

Figure 10: Surface configuration of top cell

for a cell stated by [3] for a single flow segment i.

$\operatorname{der}(\mathrm{Us}[i])=\mathrm{Hb} \_f l o w s[i]+I b \_f l o w s[n]+Q b \_f l o w s[i]$

Figure 9 shows the code for the computation of vector Q_dot_radconv for $\mathrm{n}$ different flow segments. An accurate implementation of heat transfer allows only the discretization of one flow segment. The vector $Q b_{-}$flows is set equal to the vector Q_dot_radconv which is determined from the heat flow vectors $q$ and q_res of the participating $m+7$ surfaces. The number of surfaces is determined from the number of slabs $m$ which are present during the simulation, the number of furnace walls, the hearth surface and the surface of the gap between slabs and hearth. For all real walls q_res is equal to 0 and q is the net heat flow due to radiation and convection. The net heat flow $\mathrm{q}$ of the slabs is set to 0 if the slab is not present in the considered cell. The vector A_agg aggregates the surface areas of all participating bodies.

\subsubsection{Wall, hearth and slab models}

The wall hearth and slab models are based on the Modelica. Thermal. HeatTransfer. Components, which provide a solution for the 1-dimensional heat conduction equation. Figure 11 shows the model of a layered wall which is discretized with the elements HeatCapacitor and ThermalConductor. The models have connectors to the heat transfer model which represents the connection to the radiative and convective trans- 


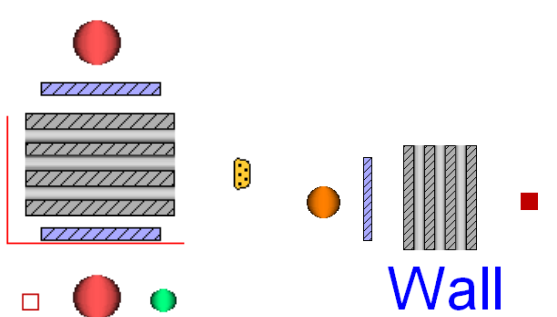

Figure 11: Layered slab and wall model

fer equations and a connector HeatPort of the Modelica.Thermal . HeatTransfer. Components which serves to set up the boundary conditions. The interface between the connectors of the cell and the Modelica.Thermal. HeatTransfer. Components is realized by a special surface element. This element represents the emitting surface and is the first discretization of the wall and it is based on the equations of a the HeatCapacitor. The slabs and the hearth are modeled in the same way as the layered wall. The slab model possesses two surface models for the heat transfer between a top cell and a bottom cell, further it has connections to the hearth for the heat transfer due to conduction and radiation as well as to the solid flow model which determines the slab position. The hearth model is split into a model for a top cell and a bottom cell and presents an equivalent system for the real configuration, because the exact geometry configuration can hardly be modeled due to the characteristics of a 1-dimensional analysis. The HearthBottom model has a connector for the cell and one for a boundary condition which is usually a temperature condition. The HearthTop model possesses connectors for the heat conduction with the slabs, the radiative and convective heat transfer with the cell, the radiative heat transfer with the slabs and a signal connector which transmits needed data for computing the phenomena mentioned before. Figure 13 shows the parameter needed for a layered wall. The number of layers, the number of discretization per layer, the thickness of the single layers and the material properties of each layer as well as the start temperatures of the different layers have to be supplied.

\section{Combustion}

The release of energy in reheating furnaces is typically realized by the combustion of gaseous fuels. The fundamental combustion calculation is utilized to deter-

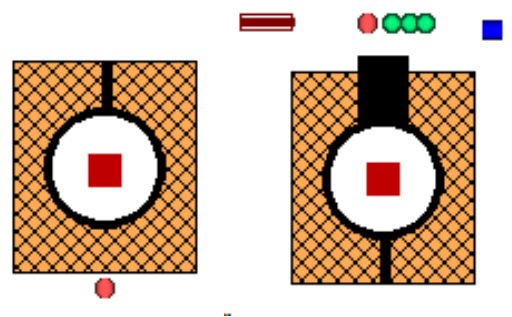

Figure 12: Hearth model for bottom and top cell

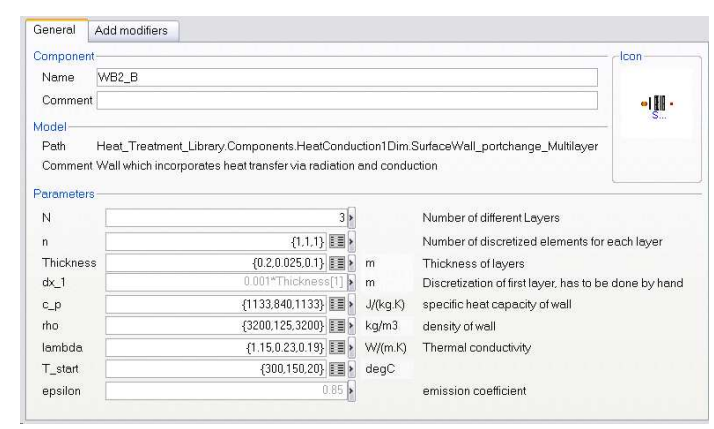

Figure 13: Parameter window for layered wall

mine the required mass flow of air, the flue gas amount and the flue gas composition. The energy input of the fuels is considered by the lower heating value $H_{u}$. The designed models neglect the dynamics of the combustion reactions. The PartialLumpedVolume serves as base class for the combustion model.The energy balance for the combustion volume is given by

$$
\begin{aligned}
\frac{\partial(\rho u V)}{\partial t}= & \dot{m}_{\text {Air }} \cdot h_{\text {Air }}+\dot{m}_{\text {Fuel }}\left(h_{\text {Fuel }}+H_{u}\right) \\
& -\dot{m}_{\text {FlueGas }} h_{\text {FlueGas }}+\sum \dot{Q}
\end{aligned}
$$

For the adiabatic combustion $\sum \dot{Q}=0$. For instance, $\sum \dot{Q}$ can be used to define heat transfer due to flame radiation but the geometric configuration and the propagation of the flame has to be known as well as the flame emissivity. The volume model has connections for the combustion air, the gaseous fuel and the flue gas. It is assumed that the entire volume is filled with homogeneously distributed flue gas. The flue gas in the volume model is completely combusted without any residues of combustibles. Three new ideal gas mixtures were defined with the Modelica.Media.Library . The mixture FuelGaseous which consists of the species $\mathrm{H}_{2}, \mathrm{~N}_{2}$, $\mathrm{CO}_{2}, \mathrm{CO}, \mathrm{H}_{2} \mathrm{~S}, \mathrm{CH}_{4}, \mathrm{C}_{2} \mathrm{H}_{2}, \mathrm{C}_{3} \mathrm{H}_{8}, \mathrm{C}_{4} \mathrm{H}_{1} \mathrm{O}, \mathrm{C}_{3} \mathrm{H}_{6}, \mathrm{C}_{2} \mathrm{H}_{2}$ and $\mathrm{C}_{4} \mathrm{H}_{8}$, FlueGas which consists of $\mathrm{O}_{2}, \mathrm{Ar}, \mathrm{N}_{2}$, $\mathrm{CO}_{2}, \mathrm{H}_{2} \mathrm{O}, \mathrm{SO}_{2}$ and Air which consists of $\mathrm{O}_{2}, \mathrm{Ar}, \mathrm{N}_{2}$, $\mathrm{CO}_{2}, \mathrm{H}_{2} \mathrm{O}$. The combustion is realized by computing the rate of change dependent on time of the single flue 


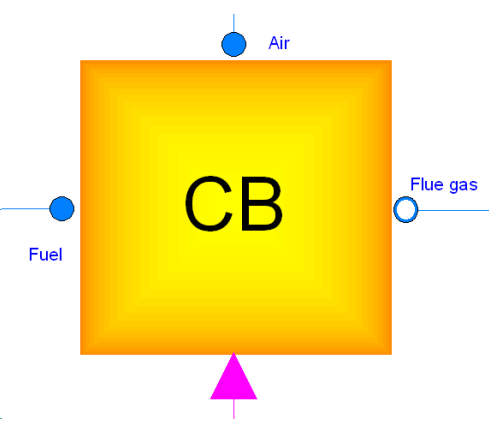

Figure 14: Volume for combustion of gases

gas masses $\frac{\partial m_{\mathrm{O}_{2}}}{\partial t}, \frac{\partial m_{\mathrm{N}_{2}}}{\partial t}, \frac{\partial m_{\mathrm{A}} r}{\partial t}, \frac{\partial m_{\mathrm{CO}_{2}}}{\partial t}, \frac{\partial m_{\mathrm{H}_{2} O} \mathrm{O}}{\partial t}, \frac{\partial m_{\mathrm{SO}_{2}}}{\partial t}$ according to the fundamental combustion equations and a predefined excess air.

\section{Solid Flow Model}

The solid flow model consists of 3 different models shown in figure 15. One model represents the heating goods, in this case slabs and therefore the SlabDistributer. It possesses the same connectors as the slabs and aggregates all slabs, which are present during simulation. The number of slabs $m$ has to be specified before starting a simulation and determines how many objects "slab" are present. Every single object slab has to be connected to each heat transfer cell, which is done via the SlabDistributer. The SlabFeedmodel is the most important element for the solid flow because it computes the position of the single slab models, refers the slab properties to the slab models and triggers the slab feed movement. Computing the slab positions and the heat transfer between slabs and the other involved bodies led to the introduction of a reference coordinate system. Therefore all models which represent geometric objects, e.g. the cells, walls slabs etc., get an origin referenced to the introduced coordinate system. The propagation of the models is specified into the positive direction of the $x(1)-, y(2)-$ and $z(3)$-axis. The fluid flow is defined positive in the positive $\mathrm{x}$-direction and the solid flow is directed against the positive $\mathrm{x}$-axis. The SlabFeed has a connection to the SlabDistributer and transmits slab position and properties. A further connection is needed via boolean input to a pulse generator. At every pulse the slabs are moved one step forward and a new slab is fed into the furnace or cell. The slab transportation occurs step wise which means they are allocated to a certain discrete position at each time step of the simulation. That means that the time of slab movement is equal to 0 . Due to the nature of a pusher

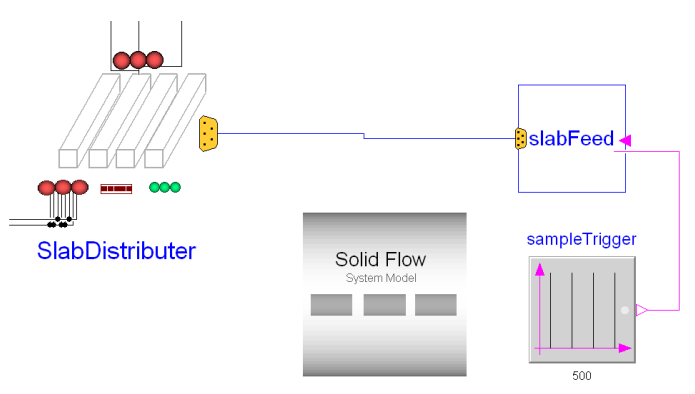

Figure 15: Solid Flow Models

type or a walking beam furnace all slabs are moved simultaneously through the cells as long as they are in the furnace. If they leave the boundaries of the furnace the slabs are brought to an end position. If more then $\mathrm{m}$ slabs are processed during one simulation the position of the completed slabs is reset to a starting position, new property values and new input temperatures are set. The SolidFlowSystem model is defined as an inner system wide component which provides important data for most of the models, e.g. maximum number of slabs in simulation, slab properties, general furnace data etc..

\section{Testing the heat transfer models}

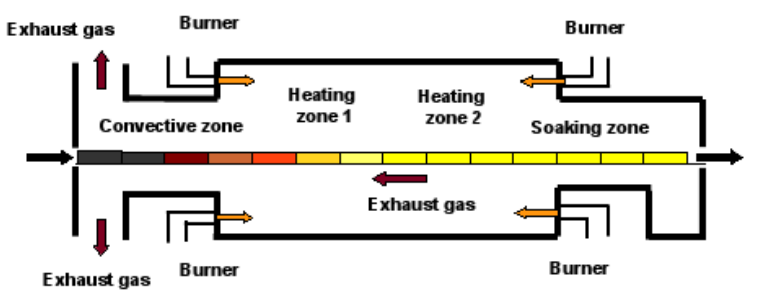

Figure 16: Configuration of reheating furnace

The heat transfer models are tested by modeling three zones of a reheating furnace depicted in figure 16. The regarded furnace incorporates two heating zones, a convective zone and the soaking zone. The reheating furnace is operated by natural gas and the energy input is evenly distributed over the two heating zones. The combustion air is preheated in a recuperator, which is not considered in the model.

\subsection{Experimental setup}

For the experimental setup the two heating zones and the convective zone are modeled. The soaking zone is neglected because it serves only to ensure that the 


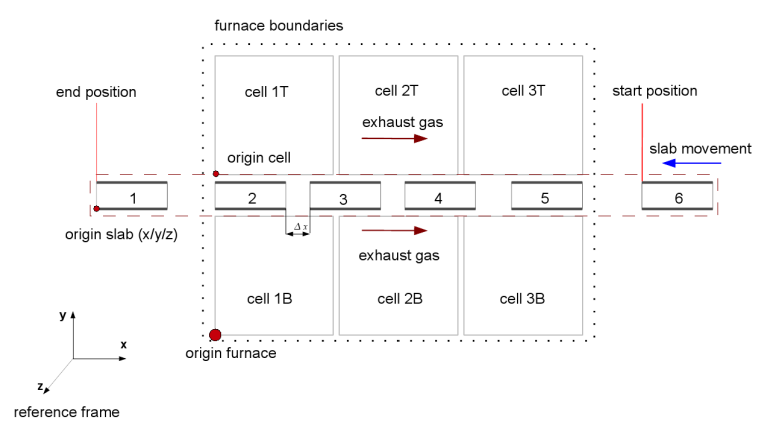

Figure 17: Discretization of furnace

core of the slab reaches the target temperature. Figure 17 shows the discretization of the furnace zones. Each zone is discretized by two cell models, a top cell model and a bottom cell model. The heating zone 1 is represented by cell2 $\mathrm{T}$ and cell2B, heating zone 2 by cell1T and cell1B and the convective zone by cell3T andcell3B. The postfix 'B' and ' $\mathrm{T}$ ' distinguish between bottom and top cells. The heating zones are equipped with 12 burners, which are modeled by the burner elements. One burner model represents 6 burners and is connected to either a top or a bottom cell. The cells of the convective zone (cell3T and cell3B) are not connected to burner elements. The top cells and bottom cells are connected via the fluid connectors and the diathermic walls among each other. Top and bottom cells are not connected via fluid connectors, there exists no fluid exchange between the top and the bottom cells. There is only an exchange of heat due to radiation between the top and the bottom cells. Furthermore the cells are connected to the wall models, the slab models and the hearth models. Figure 18 and 19 show the burner elements and the connected cell model. Figure 20 shows the whole configuration in Dymola.

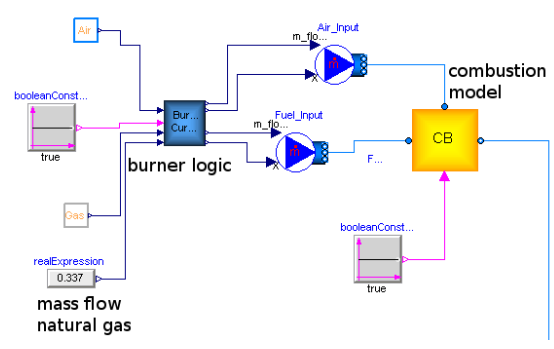

Figure 18: Model of burner elements

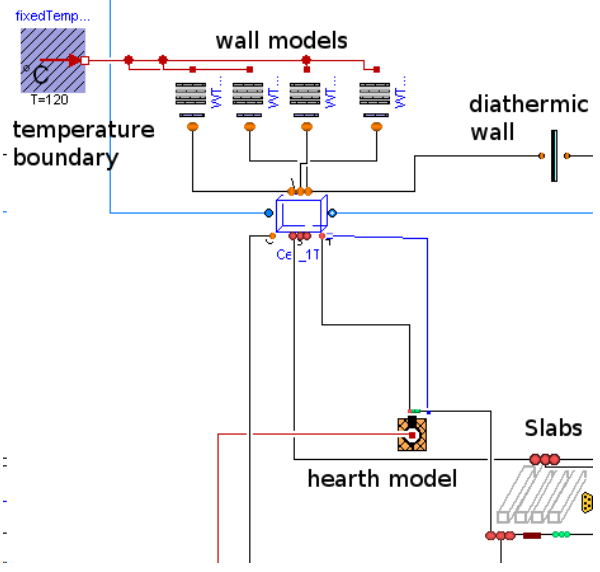

Figure 19: Model of connected cell and wall models

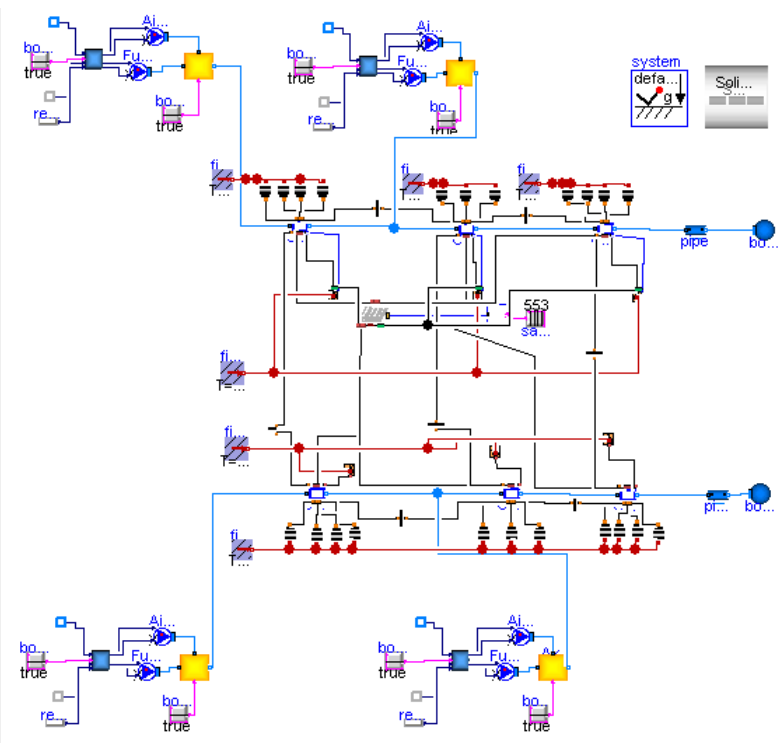

Figure 20: Model of the furnace zones in Dymola

\subsection{Simulation}

For the simulation of the modeled furnace configuration the number of slab objects was set to $m=25$. That implies a maximum number of 25 slabs can be simultaneously processed by the furnace. Each slab is discretized into 5 layers subdividing the thickness of the slab and two surface elements. It is necessary to set start positions and temperatures for the slabs, which is basically done via the solid flow model. The walls are built of different layers of refractory, which are common for those type of furnace, each layer is equal to a discretization of the heat conduction model. The outside connectors of the walls and further the wall models need proper temperature start values. The cells have a fixed position according to a reference coordinate system and values for the propagation in $x-, y-$ 
and z-direction. The position of the cell origin is important for the calculation of the view factors. The furnace has a length of $26.5 \mathrm{~m}$ in $\mathrm{x}$-direction. The heat conduction between slabs and the hearth had to be prevented because of high values of the cell dimensions ( $8 \mathrm{~m}$ to $10.5 \mathrm{~m}$ ) in $\mathrm{x}$-direction compared to the width of the $\operatorname{slabs}(\approx 1.5 \mathrm{~m})$. The heat conduction between the slabs and the hearth of each cell is computed with the mean temperature of all slabs which are present in a cell. The energy input via the burners is set constant for the whole simulation time at $68.75 \mathrm{MW}$, the heating value of the natural gas is set to $48.9 \mathrm{~kJ} / \mathrm{kg}$, the single constituents of the gas remain constant during the simulation and the temperature of the preheated combustion air is set to $350^{\circ} \mathrm{C}$. The emissivity of all walls and the hearth is set to 0.9 and of the slabs to 0.8 . The slab movement starts after $500 \mathrm{~s}$ and after the duration of $553 \mathrm{~s}$ the slabs are moved one step forward as well as a new slab is fed into the furnace. The value of the forward step is determined by the $\mathrm{x}$-dimension of the incoming slab. $15000 \mathrm{~s}$ of the furnace operation are simulated by using the integration algorithm RadauIIa for stiff systems. The integration time for the simulation of 15000 s lasted 1711.39 s.

\subsection{Results}

Figure 21 shows the temperature distribution over the simulation time of two different slabs. Figure 22 shows the discrete position of the slab origin over simulation time of the slab 19, furthermore it depicts the position during a whole pass of the slab element through the furnace. The dimensions of slab 19 at that time are $L(x)=1.397 m, H(y)=0.218 m$ and $D(z)=$ $12.12 \mathrm{~m}$. At $1053 \mathrm{~s}$ the slab 19 is fed into the furnace. The processing of the slab ends at $11560 s$ which gives a time of residence of about $10507 \mathrm{~s}$. At the end of processing slab 19 has a surface temperature of $1351^{\circ} \mathrm{C}$ at the top and a temperature of $1335^{\circ} \mathrm{C}$ in the middle layer. The surface temperature at the bottom shows to be similar compared to the top temperature. The temperature rise of the slabs show also the transport from one zone into another by a change in the temperature slope. After the heating process slab 19 is fed to an end position where new properties and dimensions can be defined, e.g. a new input temperature. Afterwards the slab is fed to a predefined position in front of the furnace where it remains until processing is started again. Figure 24 shows the temperature distribution of the gas and the top wall of the top cells. It can be seen that the temperature is strongly influenced by the incoming and outgoing slabs. During the slab movement a high amount of energy contained in the outgoing slab is leaving the system and another much lower amount of energy connected to the incoming slab is entering the system. The resulting difference in enthalpy leads to a temperature drop at each slab movement. Figure 25 shows the emissivity and the absorptivity of gas for the irradiating top wall oaf cell1T. The emissivity depends on the gas temperature but it is independent from the wall temperature. As expected it decreases with increasing temperature. The absorptivity of the gas depends on the temperature of the irradiating wall, as a result it has not the same values as the emissivity of the gas.

\section{Conclusion}

Components for modeling dynamic heat transfer in industrial furnaces like pusher-type or walking beamtype have been developed. They can be used to model single zones or entire furnace systems. Those physical models would be particularly suitable for designing advanced control concepts for the operation of the furnaces. The simulation of the test configuration shows satisfactory results. The most important future task is the validation of the heat transfer models by modeling an existing reheating furnace and comparing the simulation with measurement results.

\section{Symbols}

\section{Symbol Physical value}

\begin{tabular}{|c|c|}
\hline$A_{i}\left(m^{2}\right)$ & surface area of wall $\mathrm{i}$ \\
\hline$a_{i}(-)$ & weighting factor gas radiation \\
\hline$b_{0 i}(-)$ & $\begin{array}{l}\text { coefficient of weighting } \\
\text { factor polynomial }\end{array}$ \\
\hline$b_{1 i}(1 / K)$ & $\begin{array}{l}\text { coefficient of weighting } \\
\text { factor polynomial }\end{array}$ \\
\hline$c_{p}(\mathrm{~J} / \mathrm{kgK})$ & specific heat capacity \\
\hline$E_{b}\left(W / m^{2}\right)$ & $\begin{array}{l}\text { hemispherical total emissive } \\
\text { power of a black body }\end{array}$ \\
\hline$F_{i j}(-)$ & $\begin{array}{l}\text { view configuration factor } \\
\text { from surface } i \text { to } j\end{array}$ \\
\hline$h(J / k g)$ & specific enthalpy \\
\hline$H_{i}\left(W / m^{2}\right)$ & $\begin{array}{l}\text { incoming radiative } \\
\text { heat flow of surface } \mathrm{i}\end{array}$ \\
\hline
\end{tabular}




\section{Symbol Physical value}

\begin{tabular}{ll}
\hline \hline & \\
$H_{u}(\mathrm{~J} / \mathrm{kg})$ & lower heating value \\
$k_{g i}(1 / \mathrm{m} \cdot \mathrm{bar})$ & $\begin{array}{l}\text { absorption coefficient } \\
\text { of species i }\end{array}$ \\
$\dot{m}(\mathrm{~kg} / \mathrm{s})$ & mass flow \\
$\dot{Q}_{e}(\mathrm{~W})$ & power source \\
$\dot{q}_{i}\left(\mathrm{~W} / \mathrm{m}^{2}\right)$ & net-radiation heat flow \\
& of surface i \\
$\dot{q}_{c o n v}\left(\mathrm{~W} / \mathrm{m}^{2}\right)$ & convective heat flow \\
& of surface i \\
$S_{G}(\mathrm{~m})$ & radiation beam length \\
$T_{i}(K)$ & temperature of wall i \\
$T_{g}(K)$ & gas temperature \\
$u(\mathrm{~J} / \mathrm{kg})$ & specific internal energy \\
$V\left(\mathrm{~m}^{3}\right)$ & volume \\
$W_{i}\left(\mathrm{~W} / \mathrm{m}^{2}\right)$ & outgoing radiative heat flow \\
& of surface i \\
$\alpha_{i}(-)$ & absorptivity of surface i \\
$\alpha_{g}(-)$ & absorptivity of gas \\
$\varepsilon_{g}(-)$ & emissivity of gas \\
$\varepsilon_{i}(-)$ & emissivity of surface i \\
$\lambda(\mathrm{m})$ & beam length \\
$\rho_{i}(-)$ & reflectivity of surface i \\
$\sigma\left(\mathrm{W} / \mathrm{m}^{2} K^{4}\right)$ & Stefan-Boltzmann constant \\
$\tau(-)$ & transmittance of gas \\
\hline &
\end{tabular}

\section{References}

[1] Clark, J. A., Korybalski, M. E., AND ArBOR, A. Algebraic methods for the calculation of radiation exchange in an enclosure. Wärme und Stoffübertragung 7 (1974), 31-44.

[2] DiETz, U. Einsatz mathematischer Modele zur Simulation industrieller Feuerräume unter besonderer Berücksichtigung des Strahlungsaustausches. PhD thesis, Universität Stuttgart, Institut für Verfahrenstechnik und Dampfkesselwesen, 1991.

[3] Franke, R., Casella, F., Sielemann, M., Proelss, K., Otter, M., And Wetter, M. Standardization of thermo-fluid modeling in modelica.fluid. In 7th Modelica Conference, Como, Italy, Sep. 20-22, (2009).

[4] Hackl, F. Eine betriebsorientierte Methode zur Berechnung der instationären tehermischen Vorgänge in Wärmeöfen. PhD thesis, Montanisitische Hochschule Leoben, 1974.
[5] KIM, M. Y. A heat transfer model for the analysis of transient heating of the slab in a directfired wlking beam type reheating furnace. International Journal of Mass and Heat Transfer 50 (2007), 3740-3748.

[6] Scholand, E. Ein einfaches mathematisches Modell zur Berechnung des Strahlungswärmeaustausches in Brennkammern, vol. Fortschr.-Ber. VDI-Z Reihe 6 Nr.111. VDI-Verlag GmbHDüsseldorf, 1982.

[7] Siegel, R., AND Howell, J. R. Thermal Radiation Heat Transfer. Hemisphere Publishing Corporationher Publishing CorporationTaylor \& Francis, 1992.

[8] STRACKe, H. Mathematisches Modell für brennstoffbeheizte Industrieöfen unter besonderer Berücksichtigung der Gasstrahlung, vol. Forschungsberichte des Landes NordreihenWestfalen Nr. 2821/Fachgruppe Maschinenbau Verfahrenstechnik. Westdeutscher Verlag, 1979.

[9] Verein Deutscher Ingenieure, V.-G. V. U. C., Ed. VDI-Wärmeatlas 10. Auflage. SpringerVerlag, 2006. 


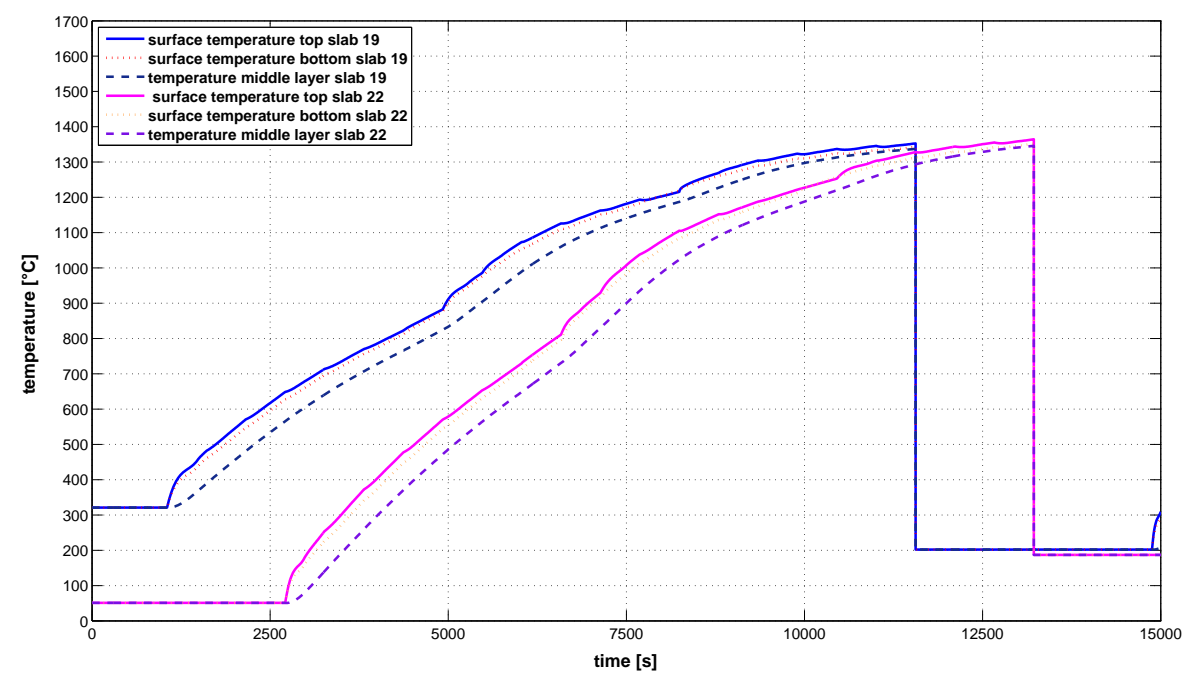

Figure 21: Slab temperature

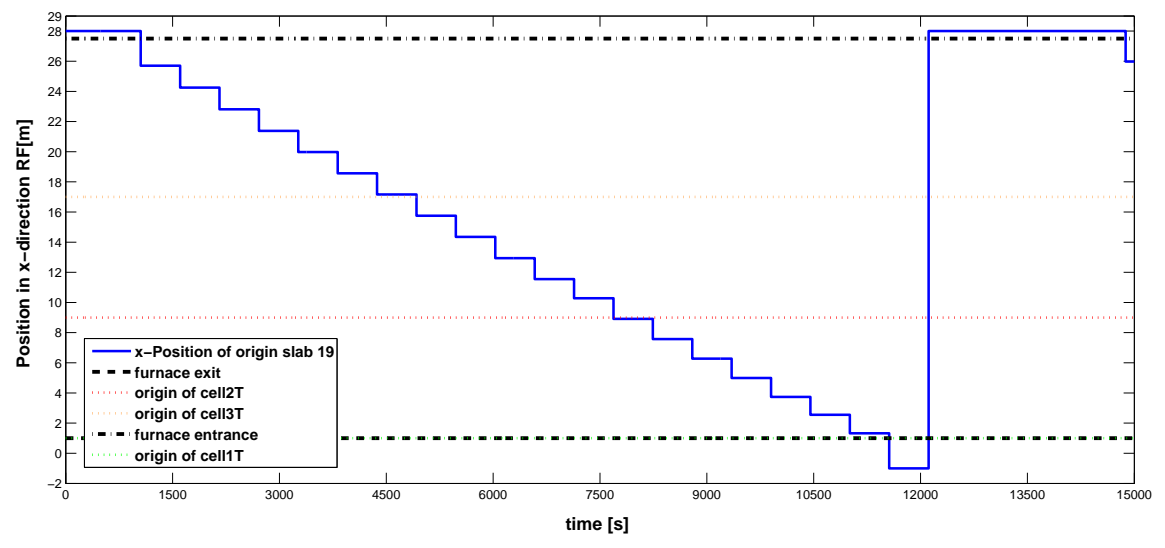

Figure 22: Discrete Slab positions during simulation

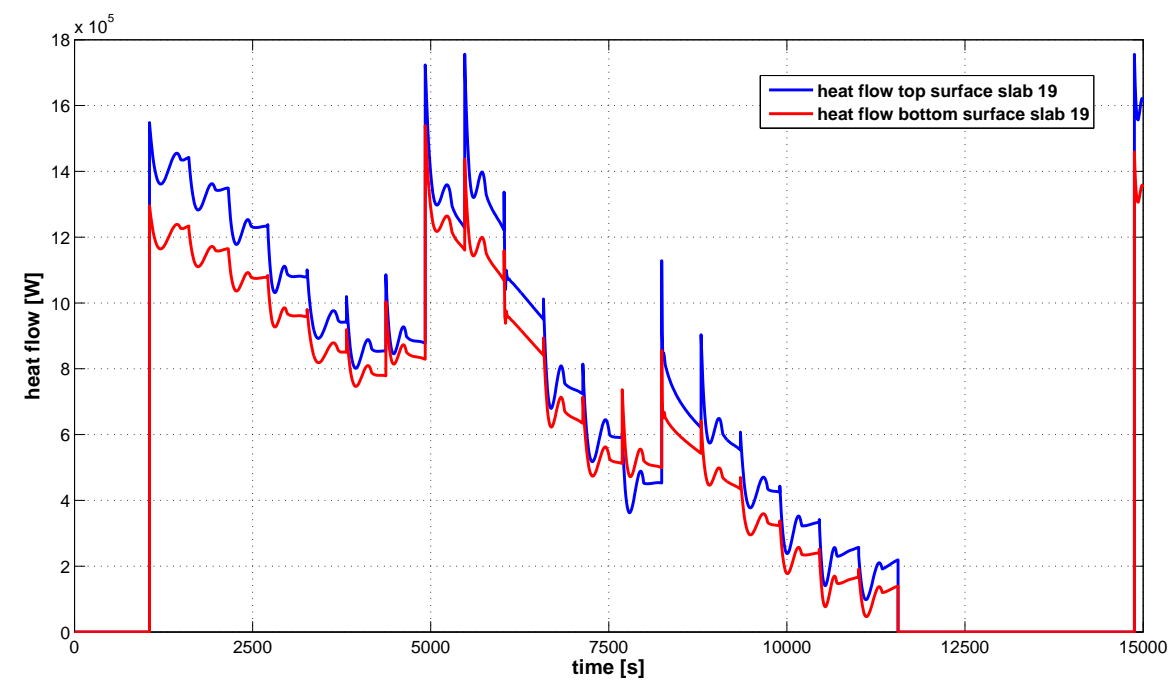

Figure 23: Heat flow at top and bottom surface of slab 19 


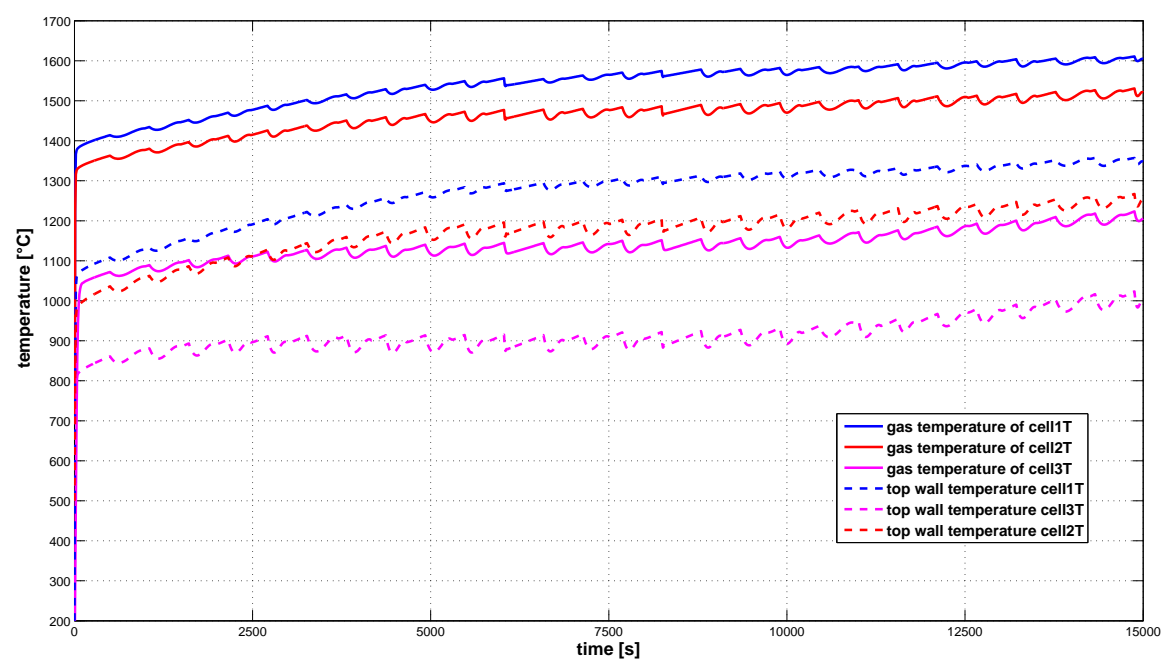

Figure 24: Gas and wall temperature of top cells

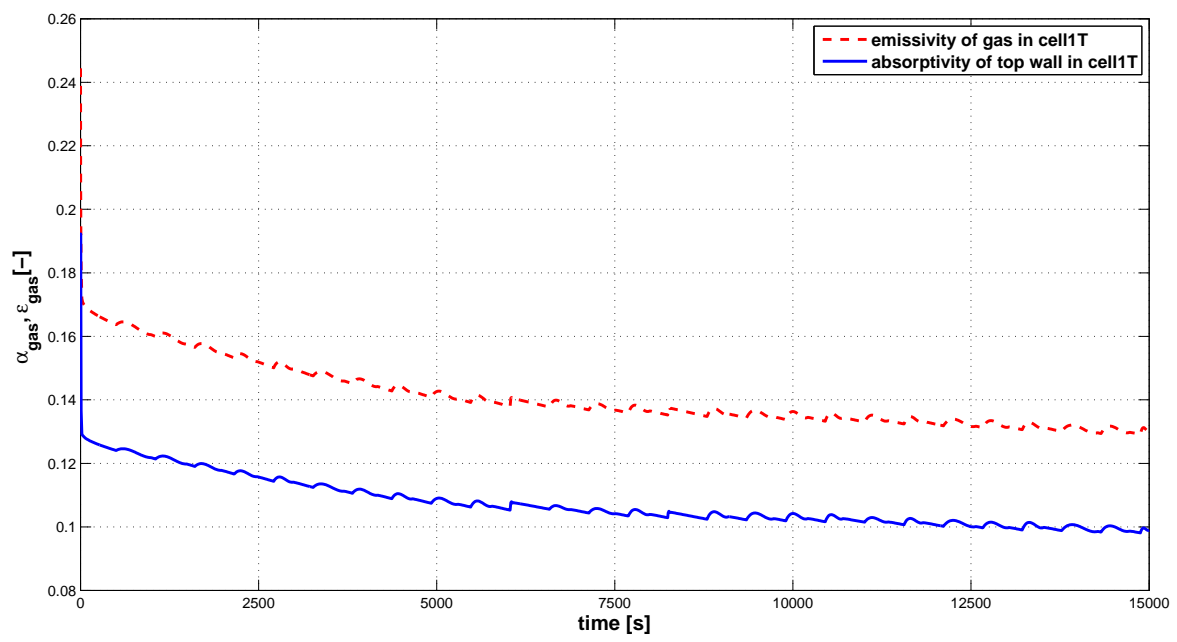

Figure 25: Gas emissivity and absorptivity 